\title{
A propósito de la teoría de las relaciones internacionales contemporáneas
}

Manuel Morales Lama'

Nota Diplomática enviada em 29.11.2009

Como disciplina, la teoría de las relaciones internacionales se ocupa del estudio del complejo de nexos que se establecen entre entes organizados en Estados, así como de los demás sujetos internacionales entre sí, o sea "entre grupos sociales fuera de las fronteras de los Estados".

En tal contexto cabe señalar que de las múltiples maneras en que el término "relaciones" es utilizado en el marco de los asuntos internacionales, merece una especial mención la "teoría de las relaciones internacionales", la cual tiene la trascendental finalidad como ciencia de observar, dilucidar y analizar, además de interpretar y predecir, los procesos de las relaciones entre los Estados del sistema mundial como un todo, con el propósito de que los creadores de decisiones de los Estados y otros actores internacionales puedan estar en condiciones de determinar aquellas políticas que presumiblemente alcancen sus propósitos e intereses, nacionales o internacionales.

Es oportuno recordar que en las Cancillerías que han establecido Programas de Investigación y Prospectiva Internacional, éstos tienen como fundamento la teoría de las relaciones internacionales y se proponen aportar mayores elementos para la toma de decisiones a corto plazo y, sobre todo, tienen la finalidad de prever los rumbos y los márgenes de acciones de una política exterior en situaciones caracterizadas por su gran fluidez.

Retrotrayéndonos a sus orígenes el término relaciones internacionales fue acuñado tempranamente (en el Siglo XIX) por Benthan Jeremy (1791), pero su

1 Diplomata dominicano. Ex-Embaixador da República Dominicana no Brasil e na Venezuela. 
consagración definitiva en el ámbito de la investigación científica es reciente, remontándose prácticamente al segundo decenio del Siglo XX. Como ciencia, las relaciones internacionales parten propiamente de la Primera Guerra Mundial. Esencialmente puede afirmarse que hasta esa época no se había investigado lo suficiente el sistema internacional como un complejo social y como un sistema político "sui generis". Como materia de estudio se origina en Estados Unidos de América con su actual nombre; relaciones internacionales. Empero, el Reino Unido de Gran Bretaña, bajo el mismo nombre de relaciones internacionales (pero también de asuntos internacionales, asuntos mundiales o política internacional), la incorporó en 1919, año en que se reconoce que la Universidad de Gales creó la primera cátedra de política internacional.

Determinados autores, entre ellos, Quince Wright, en su obra The Study of International Relations (1995, p. 8)", coinciden al afirmar que el insistir en tratar de estudiar las relaciones internacionales como una disciplina autónoma, con un campo de estudio propio, ha sido el fruto de consideraciones de tipo práctico más que de carácter teórico. Y tiende a concebirla como materia multidisciplinaria.

En la misma dirección, Héctor Cuadra considera que "La teoría de las relaciones internacionales no es, pues, la política internacional, sino la ciencia y teoría que extrae los principios científicos de aplicación general para la interpretación de la acción de los Estados como sujetos activos o pasivos de la política internacional, con referencia a acciones pasadas, presentes y en cierne" (CUADRA, 1986, p. 31). De igual manera, el citado autor e investigador afirma: "Las relaciones internacionales como disciplina trae o debe traer implícito el término de teoría de las relaciones internacionales o ciencia de las relaciones internacionales, y no tiene nada que ver, en este sentido, con las situaciones reales de interacción entre los Estados, es decir, las relaciones internacionales en sí mismas. En otras palabras, las relaciones internacionales, no deben ser confundidas con ésta, la cual debería más propiamente denominarse sociología de la política internacional” (CUADRA, 1986, p. 31).

Indudablemente, la teoría de las relaciones internacionales se ha convertido en una disciplina indispensable de los Estudios Diplomáticos oficiales, y también de los Estudios Internacionales que ofrecen instituciones privadas y autónomas. 
Conviene recordar que en las relaciones diplomáticas los actores suelen ostentar la representación del propio Estado. En consecuencia, las exigencias para la debida formación integral de éstos suelen ser mayores que las consabidas para otros ejercicios profesionales. Más aún para quienes asumen responsabilidades de naturaleza formativa en este ámbito, cuya eficacia depende ineludiblemente de que puedan cumplir a plenitud con los requerimientos vocacionales y conceptuales pedagógicos, con el dominio cabal de los fundamentos académicos y así mismo contar con el imprescindible soporte de una vasta cultura y de una esmerada educación, y sobre todo de una sólida formación que sustente campos esenciales como la ética y la moral. Es evidente que no se puede pretender ser educador en esta área sin la calidad humana y profesional correspondiente. En igual sentido, hay que destacar que la formación integral requerida en este ámbito, tiene el esencial propósito de garantizar, en la medida de lo posible, el comportamiento digno y respetuoso que debe caracterizar el ejercicio del diplomático en propiedad.

Recuérdese finalmente que "como afirma la Corte Internacional de Justicia, el régimen de las relaciones diplomáticas viene a ser un edificio jurídico pacientemente construido por la humanidad en el curso de los siglos, cuya salvaguarda es esencial para la seguridad y bienestar de una comunidad internacional compleja como la actual" (QUÉL LÓPEZ, 1993, p.7).

\section{Referências}

BARSTON, R. P. Modern diplomacy. New York: Longmans, 1988.

BELLENGER, Lionel. La nègociation. París: Presses Universitaires de France, 1987.

BENTHAM, Jeremy. El panoptico. CARTA DEL SEÑOR JEREMY BENTHAM AL SEÑOR J. PH. GARRAN, DIPUTADO ANTE LA ASAMBLEA NACIONAL. Dover street, Londres, a 25 de noviembre de 1791.

BURTON, J. W. Teoría general de las relaciones internacionales. México: UNAM, 1986.

CUADRA, H. La teoría de las relaciones internacionales In: BURTON, J. W. Teoría general de las relaciones internacionales. México: UNAM, 1986. 
DE OLLOQUI, José Juan. La diplomacia total. México: FCE, 1994.

DEPETRE, José Lión. Derecho diplomático. México: Textos Universitarios, 1974.

GONÇALVES DA SILVA, Carlos A. Direito internacional moderno. Belo Horizonte: Mandamentos, 2004.

JARA RONCATI, Eduardo. La función diplomática. Santiago: PNUD/Cepal, 1989.

MORALES LAMA, Manuel. Diplomacia contemporánea: teoría y práctica, para el ejercicio profesional. Santo Domingo: Fundación Antonio M. Lama, 2004.

MORENO PINO, Ismael. La diplomacia: aspectos teóricos y prácticos. México: Secretaría de Relaciones Exteriores, 1996.

NARVÁEZ RIVADENEIRA, Luis: La Diplomacia y las negociaciones internacionales. In: SECRETARÍA DE ESTADO DE RELACIONES EXTERIORES. La nueva política exterior dominicana y temas de relaciones internacionales. Santo Domingo, 1998.

PASTOR RIDRUEJO, José A. Curso de derecho internacional público yorganizaciones internacionales. Madrid: Técnos, 1996.

PÉREZ DE CUÉLLAR, Javier. Manual de derecho diplomático. México: Fondo de Cultura Económica, 1997.

POTEMKIN, Vladimir Petrovich. Historia de la diplomacia. México: Grijalbo, 1966.

QUEL LOPEZ, F. J. Los privilegios e inmunidades de los agentes diplomáticos en el derecho internacional y en la práctica española. Madrid, 1993.

TRINDADE, Antônio Augusto Cançado. A nova dimensão do direito internacional. Brasília: Instituto Rio Branco, 2003.

RAMACCIOTTI, Beatriz. Derecho internacional público. Lima: Pontificia Universidad Católica del Perú, 1993.

RENOUVIN, Pierre. Historia de las relaciones internacionales. Madrid: Akal, 1982.

SEITENFUS, Ricardo. Direito das relações internacionais. Porto Alegre: Livraria do Advogado, 2002. 
SEPÚLVEDA, César. Derecho internacional. México: Porrúa, 1988.

TOBAL, Vinicio. El arbitraje internacional. Santo Domingo: Alfa \& Omega, 1998.

VERDROSS, Alfred. Derecho internacional público. Madrid: Biblioteca Jurídico Aguilar, 1976.

WOOD, John R.; SERRES, J. Diplomatic ceremonial and protocol. New York: Columbia University, 1979.

WOODFORD, Protese E.; SCHMITT, Conrad J. Ciencia politica y relaciones internacionales. New York: McGraw-Hill, 1993.

ZORBIBE, Charles. Les relations internacionales. París: PUF, 1975. 
